\title{
Autour de l'autel chrétien médiéval, II
}

Dijon, 16 mai 2003

\section{Alain Rauwel}

\section{(2) OpenEdition}

Journals

Édition électronique

URL : https://journals.openedition.org/cem/908

DOI : $10.4000 / \mathrm{cem} .908$

ISSN : 1954-3093

Éditeur

Centre d'études médiévales Saint-Germain d'Auxerre

Édition imprimée

Date de publication : 15 août 2004

ISSN : 1623-5770

Référence électronique

Alain Rauwel, «Autour de l'autel chrétien médiéval, II », Bulletin du centre d'études médiévales d'Auxerre | BUCEMA [En ligne], 8 | 2004, mis en ligne le 20 décembre 2006, consulté le 22 septembre 2022. URL: http://journals.openedition.org/cem/908 ; DOI : https://doi.org/10.4000/cem.908

Ce document a été généré automatiquement le 22 septembre 2022.

Creative Commons - Attribution - Pas d'Utilisation Commerciale - Partage dans les Mêmes Conditions 4.0 International - CC BY-NC-SA 4.0

https://creativecommons.org/licenses/by-nc-sa/4.0/ 


\section{Autour de l'autel chrétien médiéval, II}

Dijon, 16 mai 2003

\section{Alain Rauwel}

1 Le 6 avril 2001, une dizaine de médiévistes, historiens des textes et archéologues, s'était réunie pour réfléchir aux problèmes spécifiques posés par l'histoire de l'autel en régime de Chrétienté ${ }^{1}$. Bien des questions restées en suspens appelaient une reprise des travaux : mission accomplie au Musée archéologique de Dijon (grâce à l'hospitalité de Christian Vernou) le 16 mai 2003.

2 Alain Rauwel (Dijon) ouvrit la journée en faisant le point des chantiers en cours : analtarité de certains espaces cultuels, localisation de l'autel, forme (bloc ou table ?), matière, dimensions, et surtout valeurs. L'autel est le lieu du Corps, mais aussi celui de la mémoire (les inscriptions d'autels), et encore celui de l'engagement, qu'il s'agisse de serment ou de profession. La "dévotion à l'autel" apparaît donc comme un phénomène complexe et divers.

3 Éric Palazzo ( СЕSCM, Poitiers) rappela ensuite que la fixité de l'autel au cœur du sanctuaire connut des exceptions fort anciennes sous la forme des "autels portatifs", dont il analysa l'abondant dossier scripturaire, matrice d'une traduction spatiale de l'ecclésiologie ${ }^{2}$.

4 Thomas Deswarte ( СЕSCM) s'attacha aussi à la question de l'aspect et de l'environnement de l'autel en étudiant un objet très caractéristique des mondes hispaniques : les "couronnes votives" d'époque wisigothique. Il montra que leur dimension de victoire et de triomphe, même si elle n'est pas exclusive, est à mettre en relation avec la réflexion doctrinale sur la royauté du Christ.

5 L'après-midi, David Lavergne (Aix-en-Provence) déplaça l'attention vers les "usages" de l'autel, aux confins de la liturgie proprement dite et des coutumes monastiques. L'angle retenu, particulièrement original, fut celui des rites de la profession. Le dépôt sur l'autel des cheveux coupés du nouveau profès, assimilant le sacrifice de la chevelure à 
celui du Sauveur, apparaît comme un bon indicateur de l'orientation christiforme de la vie consacrée.

6 Les deux dernières contributions, par un tout autre biais, rejoignirent cette dimension d'assimilation au Christ. Emmanuel Mouraire (Menton) et Laurent Durnecker (Université de Bourgogne) posèrent en effet le problème de la présence des "reliques" des saints sur ou autour de l'autel. Le premier prit l'exemple de l'abbatiale de Cîteaux, où une riche documentation d'époque moderne permet de connaître précisément vocables et reliques des autels principaux et secondaires ${ }^{3}$. Le second, à partir de plusieurs sanctuaires bourguignons, s'intéressa plutôt aux châsses des corps saints dans leur position par rapport à la table eucharistique. Il proposa une véritable typologie des situations possibles, croisant les préoccupations symboliques et la prise en compte d'impératifs plus pragmatiques, liés à la visibilité et au contact.

Qu'il y ait stabilité ou itinérance, qu'il s'agisse de couronnes, de cheveux ou de reliques, l'unité thématique est évidente : l'autel, locus proprius de la rédemption en acte, polarise l'espace chrétien et sacralise les gens et les choses à mesure qu'ils entrent dans sa proximité. D'une manière qui n'est pas seulement métaphorique, l'axe de Chrétienté passe toujours par lui.

8 Suite et fin de cette réflexion collective à Dijon à l'automne 2005.

\section{NOTES DE FIN}

1. Cf. Études \& Travaux, 5, 2000-2001, p. 62-65.

2. Cf. E. PALAzzo, "Les mots de l'autel portatif", Les Historiens et le latin médiéval, Paris, Publications de la Sorbonne, 2001, Paris, p. 247-258.

3. Cf. E. MOURAIRE et P. VERNET, "Reliques et autels : les trésors de sainteté à l'abbatiale de Cîteaux", Le Cavalier d'or, fasc. 1, 1999, p. 12-19.

\section{INDEX}

Mots-clés : autel 